\title{
Influences of Governance and Economic Development Level on Happiness in High Income Asian and European Countries
}

\author{
Muhammad Asraf Abdullah', Jerome Kueh Siew Hui², Audrey Liwan ${ }^{3}$, \\ Rosita Hamdan ${ }^{4}$ and Cathrine Chan Bao Hui ${ }^{5}$
}

\begin{abstract}
This study explores the relationship between governance and human development indicators with happiness using the panel data fixed effect and random effect estimation approach. Findings from the study stress on the importance of good governance in influencing life satisfaction. In a way, good governance stimulates happiness in a positive manner. Governments in developed countries in Asia and Europe may increase happiness and promote equality through enhancements in the quality of governance. This can be done by ensuring good practices in managing the economy and resources of the country. However, the relationship between the economic development level and happiness is inconclusive and insignificant.
\end{abstract}

Field: Economics and Finance

JEL: G38, I31, O10

Keywords: Governance, Human Development Index, Happiness, Subjective Wellbeing

\section{Introduction}

For decades, economists in the field of development have strived to find the best measure for ensuring the happiness of the society. There are a number of organizations that provide the measurements for happiness such as the international survey programme named the Euro Barometer since 1973; the World Value Survey since 1980 and recently Veehoven (2005) who has provided a comprehensive measure of happiness across 155 nations. The happiness index has been widely used recently by policy makers to provide an ideal measure for social progress and goal of public policy (World Happiness Report 2015). One of the critical questions in achieving economic development is whether economic growth and development can be translated into happiness. Hence, the main objective of economic growth and development is to ensure societies are satisfied with their lives as their countries are climbing up the ladder of economic development. What is the meaning of having a

\footnotetext{
${ }^{1}$ Corresponding author: Dr. Muhammad Asraf Abdullah, Faculty of Economics and Business, Universiti Malaysia Sarawak, Malaysia, Email: amasraf@unimas.my.

${ }^{2}$ Dr. Jerome Kueh Siew Hui,Faculty of Economics and Business, Universiti Malaysia Sarawak, Malaysia, Email: ksjerome@unimas.my.

${ }^{3}$ Audrey Liwan,Faculty of Economics and Business, Universiti Malaysia Sarawak, Malaysia,

Email: laudrey@unimas.my

${ }^{4}$ Dr. Rosita Hamdan,Faculty of Economics and Business, Universiti Malaysia Sarawak, Malaysia, Email: hrosita@unimas.my.

${ }^{5}$ Cathrine Chan Bao Hui,Faculty of Economics and Business, Universiti Malaysia Sarawak, Malaysia,

Email: catmeowmeow92@gmail.com
} 